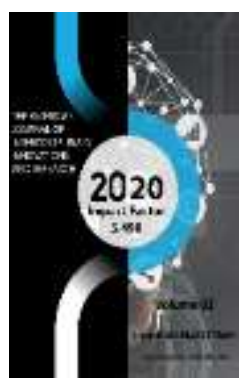

\title{
Advantage And Methodological Problems Of Teaching Computer Science In Modern Schools
}

\author{
Rasulov Inom Muyidinovich \\ Doctor Of Philosophy In Pedagogical Science, Head Of The Department Of Distance \\ Education, Qoqon State Pedagogical Institute, Uzbekistan
}

Journal Website: http://usajournalshub.c om/index,php/tajiir

Copyright: Original content from this work may be used under the terms of the creative commons attributes 4.0 licence.

\section{ABSTRACT}

The main task of scientists and teachers is to inform students about current issues in today's rapidly evolving information and communication technologies. The reason is that science is developing so fast that if this knowledge is not delivered to students today, it may become obsolete tomorrow. Scientific and practical conferences held in educational institutions also play an important role in the implementation of such important tasks.

\section{KEYWORDS}

Information, education, global progress, opportunity, communication technology, social programs

\section{INTRODUCTION}

The global process of forming an automated information society will enable human development and the solution of many economic and social problems. However, the opportunity is available only to members of the public who have the neccessary knowledge and skills in the field of information.
Therefore, one of the main tasks of secondary education is to enable younger generation to comprehensively improve the information culture and its ideological framework. The direction of computer science play and important role in solving this problem. Therefore, it is important to organize and 
analyze the priorities of the computer science course and its future prospects. Before considering the problem and prospects of teaching computer science in school, we need to consider the fundamental problem.

\section{MATERIALS AND METHODS}

That is, to develop students' understanding of the role of computer science as a science and the goal and objective of its other branches. By introducing internet, social networks, blogs, elibraries, e-books and digital audio-photovideo, mobile phones, instant messaging, IP telephony PDA and communicators, we created In the minds of modern readers that 20 years ago we lived in an information vacuum, there was nothing but social, geographical, political barriers.

Informatics is a general science and should be viewed from a structural point of view, which is determine by the specific features and functions of secondary education. The difficulty of accepting informants as a science is that its problem also apply to the science of physics, mathematics, astronomy and informatics is interdisciplinary.

Today children should not be limited to the knowledge of the existence of the computer, they should not only have an idea it, but also work freely and know how to use the technique.

Informatics is not about objects or processes, but about the methods, means and technologies of their automation, creation and operation.

According to the latest data provided, in particular, by the Internet, at present the largest universities in Russia make the most of innovative technologies in the learning process; periodically hold seminars and conferences on the introduction of innovative technologies. They are attended by both specialists of institutions of higher professional education, as well as teachers of general education schools. Let us emphasize that education in universities using innovative technologies is always open tmodern scientific research. In the curriculum of such universities there are necessarily such forms of training as project development, training, internships in production, and participation in research organizations.

\section{RESULT AND DISCUSSION}

Considering in this connection the technological aspect of education in higher education institutions, we note that currently the most personally oriented and information technologies for teaching are most widely used in them. Personally oriented technologies are represented by technologies of differentiation and individualization of instruction, project technologies, etc. The main forms of using information technologies are the following:

1) Multimedia lessons, which are held on the basis of computer-based training programs;

2) Lessons based on author's computer presentations during lectures, seminars, laboratory works, student reports. So, with the help of a computer program PowerPoint teachers organize a series of multimedia lessons, training modules, electronic textbooks, which allow the integration of audio-visual information presented in various forms - graphics, slides, text, video, etc.;

3) Testing on computers;

4) Telecommunication projects, working with audio and video inventory online;

5) Distance learning, which includes all forms of educational activity, carried out without the personal contact of the teacher and student. In today's global Internet, almost 
any educational services are offered, from short-term courses of continuing education to full-fledged higher education programs;

6) With an interactive tablet Smart Board;

7) Voice chat over the local network, used to teach phonetics. So, for the implementation of the chat applied Freeware Net Speakerphone or the Speaker, allow you to communicate in any mode: teacher-student, student-student conference mode;

All this is aimed at creating a foreign language environment in the process of teaching foreign languages, to achieve these goals, technical means of instruction are used. For example, computer-training programs in foreign language classes allow the following forms of work: pronunciation; work on grammatical material; vocabulary expansion; training in writing; training monological and dialogical speech, etc.

\section{MATERIAL AND METHODS}

Informatics- means the method of receiving, presenting, processing, storing, disseminating and managing information with the help of information technology tools. As can be seen from this definition, informatics answers the following questions:

1. How to receive and store information?

2. How should information be processed and made human-friendly?

3. How to use information technology with high efficiency?

4. How to use other science advances to create new information technologies.?

5. How to manage hardware using software?

The goal and objective of computer science are as follows.
To establish the use of the computer as an ancient in daily mental activity.

To provide knowledge about information culture and its importance.

To provide understanding of modern telecommunications and virtual reality.

Access to information technology.

However, it is important to understand that each teacher follows the following: the computer in the educational process is not a mechanical teacher or his deputy; he is a means of strengthening and expanding the possibilities of his educational activity. The teacher in this case is organizing cognitive activity of students, trying to use interactively, for example, situational model training; use creative methods, including the latest techniques (case studies, role plays, business games, dialogues, debates, seminars, conferences, abstracts, etc.), so as to solve the problems of the quality of education with the help of innovative teaching technologies.

\section{CONCLUSION}

In conclusion, it should be noted that the distribution and efficient use of information recourse can save energy, minerals, materials, equipment and other human resources.

As we live in the age information technology, each of us need to know how to use technology and keep abreast of new information in this area.

\section{REFERENCES}

1. Johns, T.F., "Some problems of a worldwide profession" in ELT Documents: The ESP Teacher: Role, Development and Prospects, British Council, 1981.

2. Science and education in the modern world: challenges of the xxi century 
3. Scientific researches for development future February 28, 2019, New York, USA

4. Karamysheva T.V. Learning foreign languages using a computer. In questions and answers. - SPb .: Publishing house "Soyuz", 2001 .-- 192 p.

5. https://multiurik.ru 